E3S Web of Conferences 1, 20009 (2013)

DOI: $10.1051 / \mathrm{e} 3$ sconf/20130120009

(c) Owned by the authors, published by EDP Sciences, 2013

\title{
Heavy metals in precipitation waters under conditions of varied anthropopressure in typical of European low mountain regions
}

\author{
A. Rabajczyk ${ }^{1}$ and H. Wróblewski ${ }^{1}$ \\ ${ }^{1}$ Department of Environmental Protection and Modelling, Jan Kochanowski University, Kielce, ul. Świętokrzyska 15G, \\ 25-406 Kielce, e-mail: chromium@tlen.pl, tel. +48 04134964 35, fax +48 0413496418
}

\begin{abstract}
The environment is a dynamic system, subject to change resulting from a variety of physicochemical factors, such as temperature, pressure, $\mathrm{pH}$, redox potential and human activity. The quantity and variety of these determinants cause the inflow of substances into individual environmental elements to vary in both time and space, as well as in terms of substance types and quantities. The energy and matter flow in the environment determines its integrity, which means that the processes occurring in one element of the environment affect the others. A certain measure of the energy and matter flow is the migration of chemical substances in various forms from one place to another. In a particular geographical space, under natural conditions, a specific level of balance between individual processes appears; in areas subject to anthropopressure, the correlations are different. In small areas, varying deposition volumes and chemism of precipitation waters which reach the substratum directly can both be observed. The study area is similar in terms of geological origins as well as morphological, structural and physico-chemical properties, and is typical of European low mountain regions. A qualitative and quantitative study of wet atmospheric precipitation was conducted between February 2009 and May 2011 in the Bobrza river catchment in the Holy Cross (Świętokrzyskie) Mountains (Poland), at three sampling sites of varying land development and distance from sources of various acidic-alkaline emissions. Field and laboratory work was conducted over 29 months, from February 2009 to May 2011. Atmospheric precipitation measurements were carried out in a continuous manner by means of a Hellman rain gauge $\left(200 \mathrm{~cm}^{2}\right)$. The collecting surface was placed at ground level (0m AGL). The application of a collecting funnel and an adequately prepared polyethylene collecting can in the rain gauge enabled the measurement of precipitation volume and water sampling for chemical analyses. In order to prevent mineral soil particles and organic matter from entering the rain gauge, the device was placed in a pit, which was - for safety reasons - covered with a grid of appropriate single net-mesh diameter. The study covered metals of $\mathrm{Fe}, \mathrm{Cd}, \mathrm{Cr}, \mathrm{Al}$ and $\mathrm{Mn}$, ions of $\mathrm{Ca}^{2+}, \mathrm{Mg}^{2+}, \mathrm{Na}^{+}, \mathrm{K}^{+}, \mathrm{NH}_{4}{ }^{+}, \mathrm{Cl}^{-}, \mathrm{F}^{-}, \mathrm{NO}_{3}^{-}, \mathrm{SO}_{4}{ }^{2-}$ and $\mathrm{PO}_{4}{ }^{3-}$ as well as the $\mathrm{pH}$ and conductivity. Basing on the conducted analyses, a characteristics of ion deposition on soil surface were developed. In order to interpret the obtained results, the neutralising potential (NP), the acidifying potential $(\mathrm{AP})$ and the acid neutralising capacity $\left(\mathrm{ANC}_{\mathrm{aq}}\right)$ indices were used, together with molar or mass proportions of the ions. The study results show a clear boundary between the northern and southern parts of the study area. Both regularities and disorders in inter-ion relationships, originating from the introduction into the air of pollution due to human activity (acidification or alkalisation), were observed.
\end{abstract}

Key words: precipitation waters, indices, metals, inorganic ions, alkalisation, acidification 